\title{
Zwitterion Formation in Gas-Phase Cyclodextrin Complexes
}

\author{
Seonghee Ahn, Xin Cong, and Carlito B. Lebrilla \\ Department of Chemistry, Department of Biochemistry and Molecular Medicine, School of Medicine, \\ University of California at Davis, Davis, California, USA
}

\section{Scott Gronert}

Department of Chemistry and Biochemistry, San Francisco State University, San Francisco, California, USA

Protonated complexes of amino acids and underivatized $\beta$-cyclodextrin, produced by electrospray ionization and trapped in the Fourier transform mass spectrometer, undergo formation of ternary complexes when reacted with alkyl amine. Based on the reactivities of the protonated amino acid complexes with alkylamines, the reactivities of the corresponding amino acid esters, and partially derivatized $\beta$-cyclodextrin hosts, we conclude that the ternary complexes are salt-bridge zwitterionic species composed of amino acid zwitterions and protonated alkylamine all interacting with the hydroxyl groups on the narrow rim of the cyclodextrin. Molecular modeling calculations and experimental results suggest that the interactions of the amino acids with the rims contribute greatly to the formation of the zwitterionic species. (J Am Soc Mass Spectrom 2005, 16, 166-175) (c) 2004 American Society for Mass Spectrometry

$\mathrm{T}$ he formation of zwitterionic structures in amino acids is of fundamental importance in biology [1-6]. The resulting electric field plays a crucial role in determining the structure of many proteins and the reactivity enzymes [7-9]. Amino acids are known to exist as zwitterions in solution under appropriate $\mathrm{pH}$ conditions. Whether zwitterions exist in the absence of solvent has been an ongoing discussion that is documented extensively in literature [10-23].

Theoretical calculations predicted that the neutral form of gas-phase glycine (Gly) is preferred by $20 \mathrm{kcal} / \mathrm{mol}[11,12]$. The same calculations show that at least two water molecules are necessary to produce a stable zwitterion structure. A subsequent theoretical study by Wang et al. support the previous calculations and suggest that a single water molecule is insufficient to stabilize the zwitterion [24]. Experimental results have suggested that the addition of five or six water molecules is needed to stabilize the zwitterions and possibly as little as three [17, 25-27]. A number of studies indicate that alkali metal ions stabilize zwitterions depending on the size of the metal ions (vide infra) [19, 21-23, 26-33].

The spectroscopic studies generally support the theoretical results regarding the stability of gas-phase zwitterions of amino acids. Millimeter wave spectroscopy has shown that Gly is not in the zwitterionic form

Published online December 15, 2004

Address reprint requests to Dr. C. B. Lebrilla, Department of Chemistry, University of California at Davis, One Shields Avenue, Davis, CA 95616, USA. E-mail: cblebrilla@ucdavis.edu in the gas phase [15], consistent with much earlier results using ion/molecule reactions [34]. Infrared (IR) cavity ringdown spectroscopy of jet-cooled arginine (Arg) showed two peaks corresponding to the neutral Arg. The absence of a band for a carboxylate asymmetric stretch confirmed that the gas-phase zwitterionic Arg did not exist in a molecular beam [13]. Gas-phase zwitterions of non-amino acids have been reported. For example, the zwitterionic 1-methylpyridinium-3,5dicarboxylate was characterized with vibrationally resolved spectra using photoelectron spectroscopy [16, 18].

Electrospray ionization (ESI) mass spectrometry has been used to produce and study the zwitterionic form of amino acids in the gas phase. An Arg dimer was obtained using ESI Fourier transform mass spectrometry (FTMS) with one of the Arg residues in the zwitterionic form [19, 20]. Zwitterionic Arg was also observed using quadrupole ion-trap mass spectrometry of Arg aggregates [14]. The ions formed stable noncovalent complexes via a strong interaction between the protonated guanidino and the carboxyl group. The stabilities of the zwitterion of alkali-cationized amino acids were measured by the collision cross sections using ion mobility methods [21-23]. It was reported that the stability of the cationized zwitterionic amino acids was proportional to the proton affinity of amino acids. This correlation with the proton affinity of amino acids provided a way to predict the structural preferences of common amino acids in the gas phase. Other metal coordinated amino acids have been reported to stabilize 
the zwitterion including transition metals [35-38]. Rak et al. even suggested that the attachment of an excess electron diminished the instability of zwitterionic amino acid [39].

The evidence supporting the existence of zwitterionic amino acid stabilized by underivatized $\beta$-cyclodextrin $(\beta-\mathrm{CD})$ will be presented. The zwitterionic amino acid was produced in the cavity of $\beta$-CD during the gas-phase reaction with alkylamine. This reaction was not observed with permethylated $\beta$-cyclodextrins $[40,41] .{ }^{\circ}$ The ${ }^{\circ}$ results ${ }^{\circ}$ of ${ }^{\circ}$ ion ${ }^{\circ}$ trap $^{\circ}$ mass $^{\circ}$ spectrometry ${ }^{\circ}$ will be presented to confirm the results obtained with FTMS. Molecular dynamics (MD) calculations was used to support the experimental results and show the existence of zwitterionic amino acid inside the $\beta$-cyclodextrin cavity.

\section{Experimental}

\section{Material}

All L-amino acids were obtained from Research Plus Inc. (Denville, NJ). 2,3,6-tri-O-methyl $\beta$-cyclodextrin $\left(\beta\right.$-CD $\left.{ }^{*}\right), 2,6$-di-O-methyl $\beta$-cyclodextrin $\left(\beta\right.$-CD $\left.{ }^{\circ}\right)$, underivatized $\beta$-cyclodextrin $(\beta-C D)$, underivatized maltoheptaose, $n$-propylamine, 1 -amino-2-propanol and ethylenediamine were obtained from Sigma Chemical Co. (St. Louis, MO). 2-Hydroxy-propyl $\beta$-CD was purchased from Aldrich Chemical Co. (Milwaukee, WI). The methylesters of leucine and phenylalanine were synthesized in our laboratory using the same method described ${ }^{\circ}$ elsewhere $[42] .{ }^{\circ}$ All ${ }^{\circ}$ chemicals ${ }^{\circ}$ were ${ }^{\circ}$ used $^{\circ}$ without further purification. The silica tubing used for the microspray tips was purchased from Polymicro Technologies Inc. (Phoenix, AZ).

\section{Fourier Transform Mass Spectrometry (FTMS)}

The experiments were performed on a home-built ESIFTMS instrument equipped with a 4.7 tesla superconducting magnet (Ionspec, Irvine, CA). The details of this instrument ${ }^{\circ}$ have $^{\circ}$ been $^{\circ}$ published $^{\circ}$ elsewhere $^{\circ}[43] .{ }^{\circ}$ The solutions of $0.01 \mathrm{M}$ amino acids and $0.01 \mathrm{M} \beta$-CD were prepared in a $50 / 50$ ( $\mathrm{vol} / \mathrm{vol})$ water/methanol solution. The complex solutions of amino acids and underivatized $\beta$-CD were prepared by 1:2 dilution and then $1 \mu \mathrm{L}$ of $0.05 \mathrm{M} \mathrm{H}_{2} \mathrm{SO}_{4}$ solution was added. Cation resin $\left(\mathrm{NH}_{4}{ }^{+}\right.$form) was added to the above solutions to avoid sodiated and potassiated species. Amine bases were introduced to the ICR cell by a variable leak valve after several freeze-thaw cycles to the pressure of $1 \sim 3 \times 10^{-7}$ torr. The flow rate of the syringe was $10-20 \mu \mathrm{L} / \mathrm{h}$ while $1.8 \mathrm{kV}$ was applied to provide spray. The temperature of the capillary was maintained at $200{ }^{\circ} \mathrm{C}$ to remove the $\beta$-CD:ammonium complexes which caused interfering exchange reactions to occur.

\section{Molecular Dynamics}

Molecular dynamics calculations were performed by using the InsightII/Discover program (Biosym Corp., San Diego, CA). For global minimization, heating/ annealing cycles were performed using consistent valence force field (CVFF) to optimize the structure of underivatized $\beta$-CD:amino acid complexes. The details of these methods ${ }^{\circ}$ were published previously $[44,45]$. To create the ternary complex with underivatized $\beta-C D$, the $\beta$-CD:amino acid complex structure was obtained through the same heating/annealing cycles. The lowest energy structure from the calculation was then used by removing the proton from the carboxyl group of the amino acid in the $\mathrm{CD}$ to the alkylmine placed in the proxymity of the narrow rim. This complex was optimized without the heating/annealing cycles, which tended to dissociate the ternary complex.

\section{Ion Trap Mass Spectrometry (ITMS)}

The results of ITMS were obtained using a modified Finnigan LCQ ion-trap mass spectrometer operating at a $\mathrm{He}^{\circ}$ background $^{\circ}$ pressure $^{\circ}$ of $^{\circ} 1.75^{\circ}$ mTorr $^{\circ}\left[46,{ }^{\circ} 47\right]^{\circ} .^{\circ}$ The solutions of the cyclodextrins and amino acid were prepared using the same procedures as for FTMS. The solution for the electrospray was made by mixing a 10:1 ratio of analyte to host and was pumped at a rate of 2-5 $\mu \mathrm{L} / \mathrm{min}$. The electrospray needle was held at $4 \mathrm{kV}$ and the heated capillary was kept at a temperature of $200{ }^{\circ} \mathrm{C}$. The $n$-propylamine was introduced into the He background by using a manifold external to the ion trap. Unlike the FTMS, the liquid n-propylamine was directly pumped (35-150 $\mu \mathrm{L} / \mathrm{h}$ ) via syringe to a fast flow of He (500-1500 $\mathrm{mL} / \mathrm{min}$ ). Rapid evaporation and mixing in the manifold lead to well-defined $\mathrm{He}$ /amine gas mixtures. When the gas mixture was applied to the LCQ's restriction capillary inlet at $3 \mathrm{lb} / \mathrm{in}^{2}$, a pressure of $1.75 \mathrm{mTorr}$ was obtained in the trap. The amine was diluted with cyclohexane before being added via the syringe pump to provide lower effective flow rates. The cyclohexane was inert and did not participate in the exchange reaction. This system allowed for the easy preparation of mixtures with $\mathrm{He} / \mathrm{amine}$ ratios ranging from 100 to 10,000:1.

\section{Results and Discussion}

Gas Phase Reaction of Underivatized

and Derivatized $\beta-C D$ :Amino Acid Complexes with FTMS

In the gas phase, amino acid complexes of derivatized $\beta$-cyclodextrins such as tri-O-methyl $\beta$-cyclodextrin $\left(\beta\right.$-CD $\left.{ }^{*}\right)$ or di-O-methyl $\beta$-cyclodextrin $\left(\beta-\mathrm{CD}^{\circ}\right)$ produced only guest exchange reactions with gaseous amines ${ }^{\circ}[41,44] .{ }^{\circ} \mathrm{As}^{\circ}$ shown $^{\circ}$ in ${ }^{\circ} S c h e m e^{\circ} 1{ }^{\circ}$ the ${ }^{\circ}$ protonated $\beta$-CD*amino acid complex, $\left[\beta-\mathrm{CD}^{*}: \mathrm{AA}+\mathrm{H}\right]^{+}$, reacts with an alkyl amine to produce the protonated $\beta-\mathrm{CD}^{*}$ : amine complex and a neutral amino acid, which is 


$$
\left[\beta-\mathrm{CD}^{*}: \mathrm{AA}+\mathrm{H}\right]^{+}+\text {Base } \rightarrow\left[\beta-\mathrm{CD}^{*}: \text { Base }+\mathrm{H}\right]^{+}+\mathrm{AA}
$$

Scheme 1. The gas-phase reaction of the amino acid complex with derivatized $\beta$-cyclodextrin (both $\beta$-CD ${ }^{*}$ and $\beta-\mathrm{CD}^{\circ}$ ) rected with gaseous amines. The amino acid was replaced by the alkyl amine base in the cavity of the $\beta$-cyclodextrin. All amino acids (AA), except Arg, undergo only guest-exchange reactions. The complexes of Arg with both $\beta-\mathrm{CD}^{*}$ and $\beta$-CD ${ }^{\circ}$ were unreactive.

released from the $\beta$-CD* cavity after the proton transfer. The net reaction is the replacement of the amino acid by the alkylamine in the cavity of $\beta$-CD* resulting in a gas-phase guest-exchange reaction.

Figure ${ }^{\circ} 1^{\circ}$ shows ${ }^{\circ}$ the ${ }^{\circ}$ FTMS $^{\circ}$ spectra ${ }^{\circ}$ of ${ }^{\circ}$ the ${ }^{\circ} \mathrm{Ala}^{\circ}(a)^{\circ}$ and Phe (b) complexes of permethylated $\beta$-cyclodextrin $\left(\beta-\mathrm{CD}^{*}\right)$ reacting with $n$-propylamine (nPA). The product ion, $\left[\beta-\mathrm{CD}^{*}: \mathrm{nPA}+\mathrm{H}\right]^{+}(1489 \mathrm{~m} / \mathrm{z})$, was observed in both spectra. The $\mathrm{Na}^{+}$- and $\mathrm{K}^{+}$-coordinated species were not completely removed during the gentle isolation step to minimize the possibility of translationally exciting the reactant ion complexes. The relative abundances of the two species were further used as internal standards to monitor ion loss, as they are unreactive to the alkyl amine. During the entire reaction period only the guest-exchange product was observed. The guest-
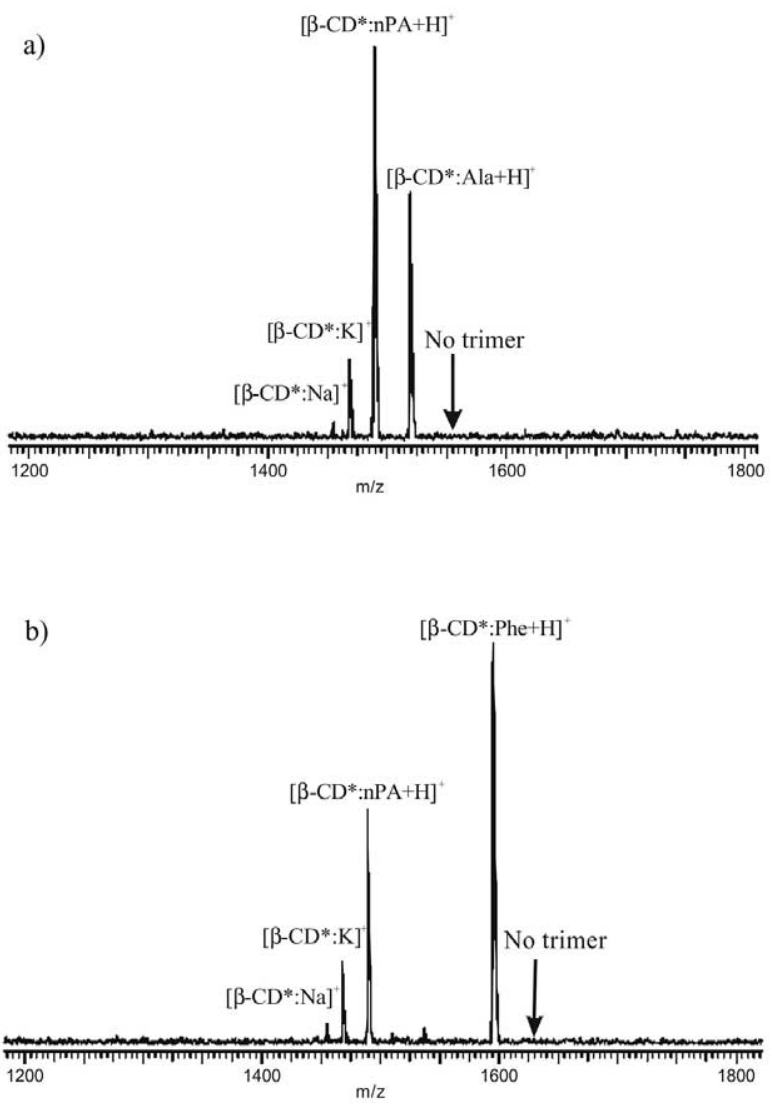

Figure 1. The reaction of $\left[\beta-\mathrm{CD}^{*}: \mathrm{Ala}+\mathrm{H}\right]^{+}$complex (a) and $\left[\beta-\mathrm{CD}^{*} \text { :Phe }+\mathrm{H}\right]^{+}$complex (b) with $n$-propylamine (nPA). Only the guest-exchanged product, $\left[\beta-\mathrm{CD}^{*}: \mathrm{nPA}+\mathrm{H}\right]^{+}$was observed in both reactions. No other products were observed with $\beta-\mathrm{CD}^{*}$ in the reaction. (The reaction time for exchange was $9500 \mathrm{~ms}$ for the Ala complex and 15,000 ms for the Phe complex.)

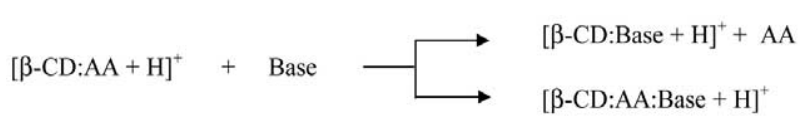

Scheme 2. The protonated complex $[\beta-\mathrm{CD}: \mathrm{AA}+\mathrm{H}]^{+}$of underivated $\beta$-cyclodextrin undergoes two types of reactions, a guest exchange reaction and a ternary complex formation. The guestexchange reactions were dominant with aminoacids such as Ala and Val, while ternary complex formation were abundant with aminoacids such as Leu and Phe.

exchange reaction was observed with amino acids (both $\mathrm{L}^{-}$-form ${ }^{\circ}$ and $^{\circ} \mathrm{D}$-form $)^{\circ}\left[41,{ }^{\circ} 44\right]{ }^{\circ}{ }^{\circ}$ rrugs $^{\circ}[44],{ }^{\circ}$ and $^{\circ}$ peptides $[44]^{\circ}$ as $^{\circ}$ guests $^{\circ}$ with $^{\circ} \beta-\mathrm{CD}^{* \circ}$ as $^{\circ}$ hosts. ${ }^{\circ}$ Reagent ${ }^{\circ}$ bases $^{\circ}$ for those studies included $n$-propylamine, ethylenediamine, 1-amino-2-propanol and s-butylamine.

In the gas-phase reaction of amino acids complexed to underivatized $\beta$-cyclodextrin ( $\beta$-CD), an additional reaction channel was observed corresponding to the formation of a ternary complex (Scheme 2). The ternary complex consisted of a $\beta$-CD with both the protonated amino acid and the alkyl amine reagent. For some amino acids, only the exchange reaction was observed as in the fully derivatized $\beta$-cyclodextrins. For example, the Ala complex produced only the guest-exchanged product $[\beta-\mathrm{CD}: \mathrm{nPA}$ $+\mathrm{H}]^{+}$(spectra not shown).

The Val complex similarly yielded primarily the guest-exchanged product. The mass spectrum of the

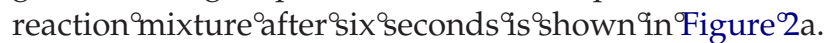
An amount $(<5 \%)$ of the ternary complex was also observed, however its intensity did not increase during the reaction period suggesting that the species was formed rapidly early in the reaction. The kinetic plot in Figure $2 \mathrm{~b}^{\circ}$ shows ${ }^{\circ} \mathrm{a}$ linear ${ }^{\circ}$ correlation $^{\circ}$ consistent $^{\circ}$ with $^{\circ}$ the presence of a single dominant component. To obtain the plot, the intensity (I) of the complex $[\beta-\mathrm{CD}: \mathrm{Val}+\mathrm{H}]^{+}$is monitored and divided by the total intensities $\left(\mathrm{I}_{\mathrm{o}}\right)$ of the reactant ion and the two product ions. For more detailed discussions the reader is refered to the following references ${ }^{\circ}\left[40,{ }^{\circ} 41,{ }^{\circ} 43\right]$.

The Leu complex $[\beta-\mathrm{CD} \text { : Leu }+\mathrm{H}]^{+}$yielded products corresponding to both the guest-exchange reaction and the formation of ternary complex with $\mathrm{nPA}$ as shown in the ${ }^{\circ}$ mass $^{\circ}$ spectrum ${ }^{\circ}$ in ${ }^{\circ}$ Figure $^{\circ} 3 a^{\circ}{ }^{\circ}$ The $^{\circ}$ kinetic $^{\circ}$ plot $^{\circ}$ of ${ }^{\circ}$ the $[\beta-\mathrm{CD}: \text { Leu }+\mathrm{H}]^{+}$complex reacting with $\mathrm{nPA}$ resulted in two ${ }^{9}$ rate ${ }^{\circ}$ constants shown ${ }^{\circ}$ in Figure $3 \mathrm{~b}$. The results'suggest that two forms of the complex $[\beta-\mathrm{CD}: \mathrm{Leu}+\mathrm{H}]^{+}$were formed during the ionization event each leading to different reaction channels (vide infra).

The reaction of Phe $[\beta-\mathrm{CD}: \text { Phe }+\mathrm{H}]^{+}$yielded primarily the ternary ${ }^{\circ}$ complex $^{\circ}$ with ${ }^{\circ} \mathrm{PA}^{\circ}$ (Figure $\left.4 a\right)^{\circ}$ with $^{\circ}$ small amount of the exchange product. As before, the trace product did not increase significantly with time and was formed in the very early part of the reaction period. ${ }^{\circ} \mathrm{A}^{\circ}$ single ${ }^{\circ}$ straight ${ }^{\circ} l i n e^{\circ}{ }^{\circ}{ }^{\circ}$ the $^{\circ}$ kinetic $^{\circ}$ plot $^{\circ}$ (Figure $4 \mathrm{~b}){ }^{\text {indicated }}{ }^{\circ}{ }^{\circ}$ single $^{\circ}$ dominant ${ }^{\circ}$ reaction ${ }^{\circ}$ corresponding to the formation of the ternary complex. 


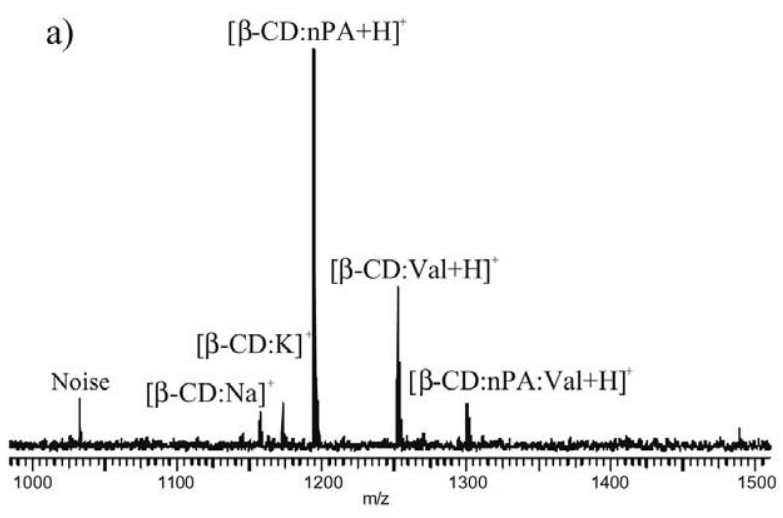

b)

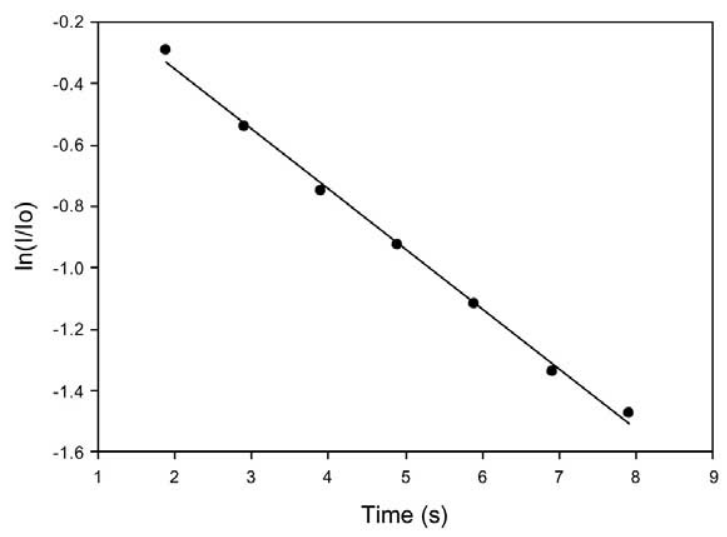

Figure 2. FTMS spectrum (a) and the kinetic plot (b) of the $[\beta-\mathrm{CD}: \mathrm{Val}+\mathrm{H}]^{+}$complex. The Val complex undergoes the guest-exchange reaction producing a single straight line in the kinetic plot.

\section{Gas-Phase Reactions of $\beta$-CD-Amino Acid Complexes with Ion Trap Mass Spectrometry}

To examine the possibility of instrument-specific artifacts, experiments were performed in an ion trap mass spectrometer. The ITMS results with nPA agreed well with the results of FTMS (spectra not shown). The Ala complex with $\beta$-CD yielded the guest-exchange reactions producing only the $[\beta-\mathrm{CD}: \mathrm{nPA}+\mathrm{H}]^{+}$complex. No trace of a ternary complex was observed. Similar observations were made with Val. The Leu complex with $\beta$-CD showed both the ternary complex and the exchange product with the ternary complex being slightly favored as was observed with the FTMS. Phe similarly yielded primarily the ternary complex as product. The ITMS experiments confirmed the production of the ternary complex in the reaction of the protonated underivatized $\beta$-CD:amino acid complex.

\section{Possible Structures for the Ternary Complex}

Molecular dynamics calculations of the amino acid complexes suggest that the protonated amine preferentially coordinates to the narrow rim of the cyclodextrin [44]..$^{\circ}$ Experimental ${ }^{\circ}$ evidence ${ }^{\circ}$ for ${ }^{\circ}$ the ${ }^{\circ}$ coordination $^{\circ}$ of ${ }^{\circ}$ the protonated amino acids with the narrow rim is presented below. With this in mind, there are at least two scenarios to account for the formation of the ternary complex (Scheme 3). In one scenario, the incoming amine approaches the narrow rim and extracts a proton from the ammonium group of the amino acid (Scheme 3a). The complex stays intact due to ion/dipole interactions particularly between the two amino groups. The other scenario involves the deprotonation of the carboxylic acid to yield a zwitterionic species stabilized by a salt bridge interaction and the interaction of the nascent zwitterion with the hydroxylated narrow rim of the cyclodextrin (Scheme $3 \mathbf{b}$ ).

The protonated amino acid complexes of underivatized cyclodextrins $[\beta-\mathrm{CD}: \mathrm{AA}+\mathrm{H}]^{+}$were calculated using molecular dynamics simulations and procedures outlined in the Experimental sections. The lowest energy structures with full optimization are presented in Figure ${ }^{\circ} 5$. The ${ }^{\circ}$ orientation ${ }^{\circ}$ f $^{\circ}$ the ${ }^{\circ}$ protonated ${ }^{\circ}$ amino ${ }^{\circ}$ acids relative to the cyclodextrin cavity consisted of two forms. In one the ammonium group interacts with the narrow (lower) rim and the carboxylic acid interacts with the wider rim ("threaded-through" orientation), while in another both the carboxylic acid and the

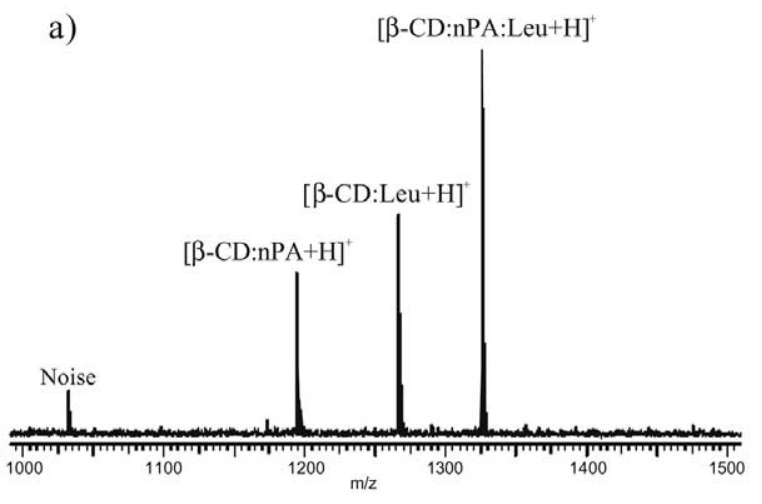

b)

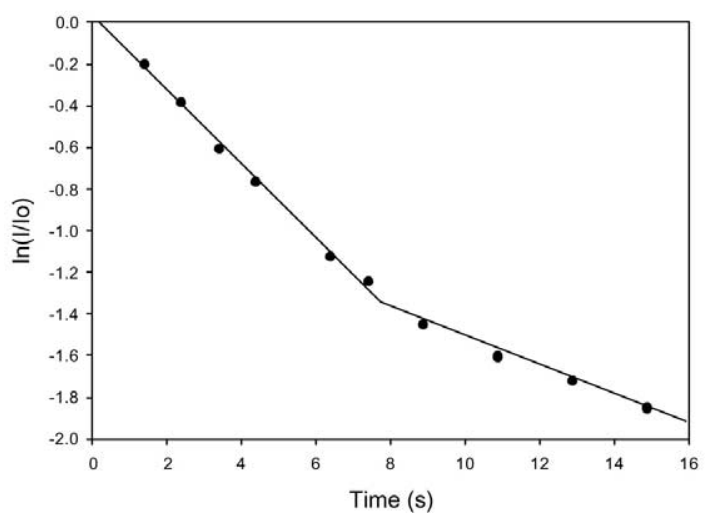

Figure 3. FTMS spectrum (a) and the kinetic plot (b) of $[\beta-C D$ : Leu $+\mathrm{H}^{+}$complex. The Leu complex undergoes both the guest exchange reaction and the ternary complex formation producing two lines in the kinetic plot. 


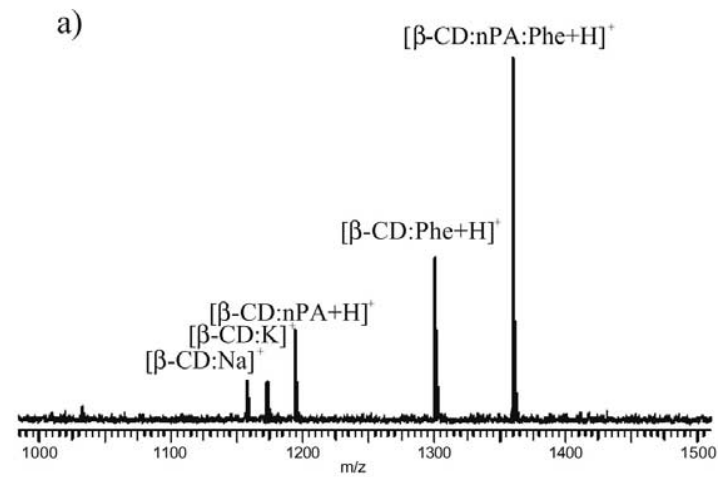

b)

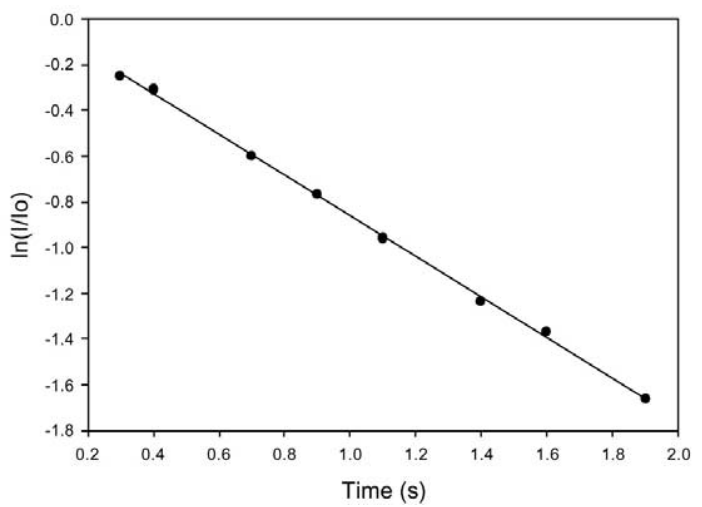

Figure 4. FTMS spectrum (a) and the kinetic plot (b) of the $[\beta \text {-CD:Phe }+\mathrm{H}]^{+}$complex. The Phe complex undergoes only the ternary complex formation producing a single straight line in the kinetic plot.

ammonium groups interact only with the narrow rim ("narrow-only" orientation). For example, the lowest energy structures of Ser involve the interaction of the ammonium group with the narrow rim while the carboxylic acid interactions primarily with the wide rim. Ala yields the same general structure and interactions

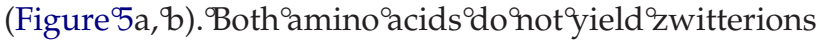
during the reaction with the alkyl amine. Conversely, Phe, Tyr, and Glu yield the types of interactions depicted $^{\circ}{ }^{\circ}{ }^{\circ}$ Figure ${ }^{\circ} 5 c^{\circ},{ }^{\circ}{ }^{\circ}$ where ${ }^{\circ}$ both $^{\circ}$ the $^{\circ}$ carboxylic $^{\circ}$ acid

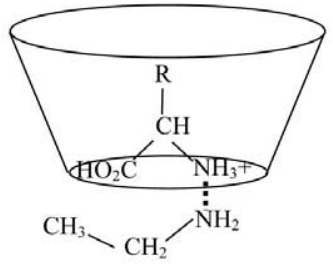

$\underline{\mathrm{a}}$

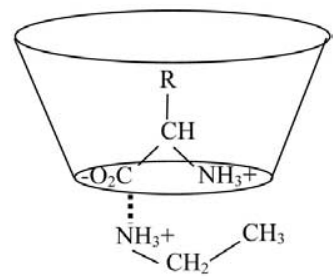

$\underline{b}$
Scheme 3. Two possible arrangements for the formation the ternary complex. (a) An ion/dipole complex consisting of an interaction between the two amino groups with one protonated. (b) A zwitterionic form with the protonated alkyl amine coordinated to the the deprotonated carboxylic acid. a) $\beta$-CD:Ala

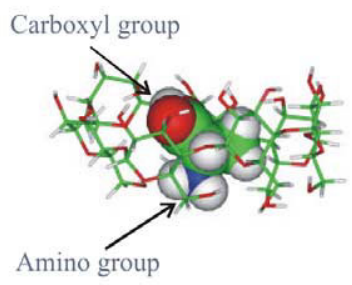

c) $\beta$-CD:Phe

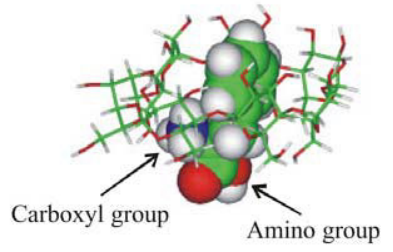

b) $\beta-\mathrm{CD}: \mathrm{Ser}$

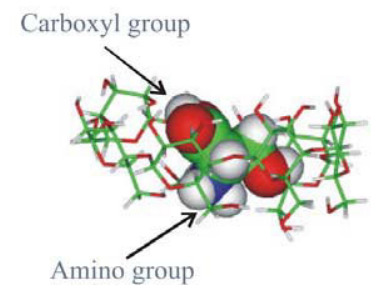

d) $\beta$-CD:Glu

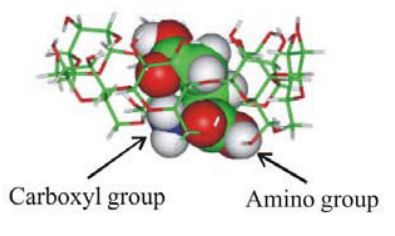

Figure 5. Low energy structures of $[\beta-\mathrm{CD}: \mathrm{AA}+\mathrm{H}]^{+}$complex. The structures clearly show that the position of Ala inside of $\mathrm{CD}$ is different from that of Phe. A Ser complex that is similar in structure to the Ala complex results in the same product, the $[\beta \text {-CD:nPA }+\mathrm{H}]^{+}$complex. The Glu complex is similar in structure to the Phe complex and behaves similarly creating a the ternary complex.

and the ammonium groups interact primarily with the narrow rim. These amino acids yield primarily the ternary complex with little or no exchange reaction products. We found general correlations between the lowest energy structure and the formation of the ternary complex. Amino acids that yielded the threadedthrough structure also produced only guest-exchange products, while those with the narrow-only structure also yielded the ternary complex. Ser and Glu further serve as illustrative examples as both have very similar basicities but very different reactivities that are consistent with their low energy structures.

The theoretical results suggest that the narrow rim is important for the stabilization of the complex. In addition, the proximity of the protonated ammonium and the carboxylic acid to the narrow rim supports the notion of extensive interactions that can stabilize the nascent zwitterion species during deprotonation the deprotonation of, presumably, the carboxylic acid. A minimized structure of a zwitterion in the cyclodextrin cavity with the nascent ammonium group on the incoming ${ }^{\circ}$ base ${ }^{\circ}{ }^{\circ} s^{\circ}$ shown ${ }^{\circ}{ }^{\circ}{ }^{\circ}$ Figure ${ }^{\circ} 6 .{ }^{\circ}$ In ${ }^{\circ}$ this ${ }^{\circ}$ structure, ${ }^{\circ}$ the zwitterion is stabilized by the hydroxyl groups of the narrow rim as it coordinates with the protonated $n$-propylamine. These hydrogen bonding interactions are important and account for the stabilization of zwitterions such as those found in gas-phase Arg clusters [20].

\section{Ion/dipole complex or Zwitterion?}

A number of experiments were performed to elucidate the nature of the interactions in the ternary complex. In 


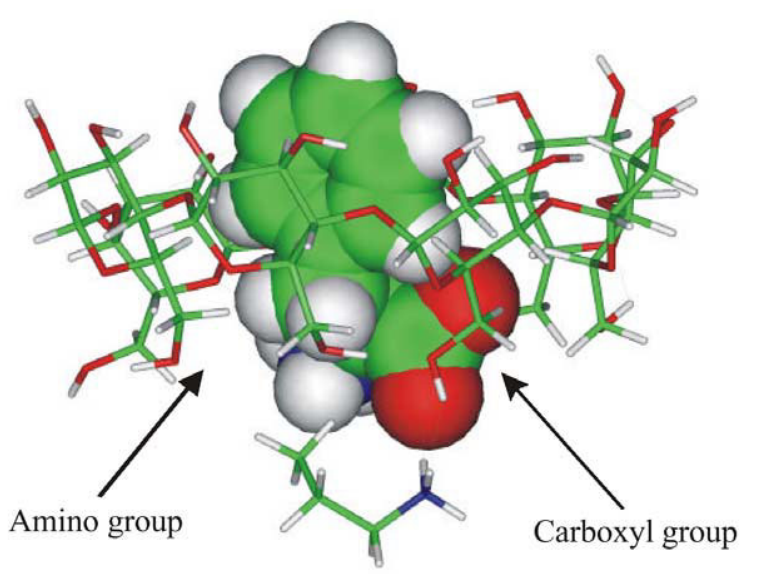

(n-Propyl amine)

Figure 6. The lowest energy structure of the ternary complex, $[\beta-\mathrm{CD}: \mathrm{AA}+\mathrm{nPA}+\mathrm{H}]^{+}$. The protonated $\mathrm{n}-\mathrm{PA}$ is coordinated with the zwitterionic phenylalanine inside $\mathrm{CD}$.

the first set of experiments, the methyl esters of a number of the amino acids and their respective cyclodextrin complexes were probed by gas-phase reaction. Ester formation removes the proton of the carboxylic acid group. If the ternary complex is simply an ion/ dipole one, it should form with or without the carboxyl group as methyl esterification changes the gas-phase basicity ${ }^{\circ}$ only ${ }^{\circ}$ minimally. ${ }^{\circ}$ Figure $^{\circ} 7^{\circ}$ shows $^{\circ}$ the ${ }^{\circ}$ reaction ${ }^{\circ}$ of the Leu methyl ester complex of $\beta$-CD [ $\beta$-CD:Leu$\left.\mathrm{O}-\mathrm{CH}_{3}+\mathrm{H}\right]^{+}$with nPA. Only the guest-exchange product $[\beta-\mathrm{CD}: \mathrm{nPA}+\mathrm{H}]^{+}$was observed. The proton bound complex of Phe methyl ester complex similarly yielded only the guest-exchange product. Based on these results, we conclude that the carboxylic acid proton is important for the formation of the ternary complex.

It may be argued that the carboxylic acid may aid in simply stabilizing the ternary complexes through intermolecular hydrogen bonding interactions between the acidic hydrogen and the protonated amine. However, similar interactions would also be present in fully derivatized cyclodextrins where only guest-exchange reactions were observed. There is apparently a stabilizing effect due to the combination of the underivatized narrow rim and the carboxylic acid group that favors ternary complex formation.

The contribution of the ion/dipole complex can be further examined by studying the effects of the differences in gas-phase basicities between the amino acid and the alkyl amine. It is well established that the strength of the ion/dipole interaction between two proton-bound species is optimal when the two compounds ${ }^{\circ}$ have $^{\circ}$ similar $^{\circ}$ gas $^{\circ}$ phase $^{\circ}$ basicities $^{\circ}(\mathrm{GB})^{\circ}\left[48,{ }^{\circ} 49\right]$.

The natural amino acids were examined with n-propylamine and ethylenediamine (EDA) to determine the correlation between gas-phase basicity (GB) and $^{\circ}$ reactivity. ${ }^{\circ}$ Table $^{\circ} 1^{\circ}$ summarizes $^{\circ}$ the $^{\circ}$ results $^{\circ}$ of $^{\circ}$ the

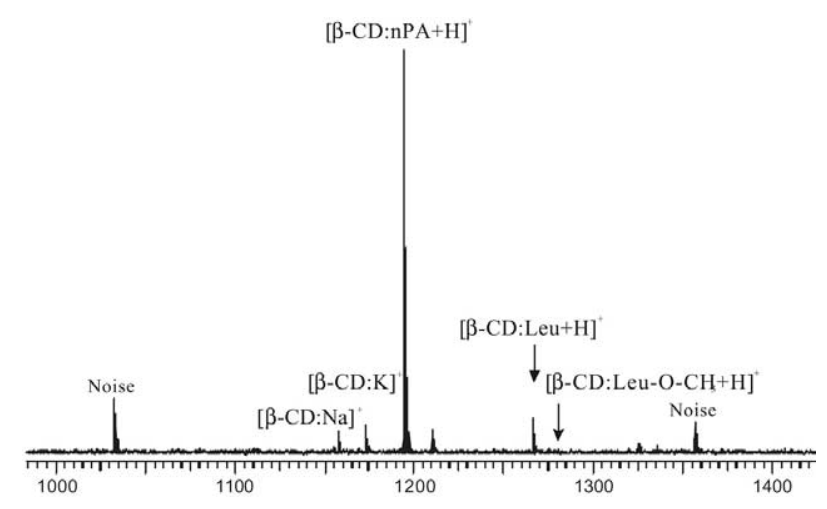

Figure 7. FTMS spectrum of the $\left[\beta-\mathrm{CD}: \mathrm{Leu}-\mathrm{OCH}_{3}+\mathrm{H}\right]^{+}$complex. Only the guest-exchanged product, $[\beta-\mathrm{CD}: \mathrm{nPA}+\mathrm{H}]^{+}$complex is produced. The result of a Leu methylester indicates that the formation of the ternary complex has to involve the deprotonation of the carboxyl group.

amino acid reactions with $n$-propyl amine. As the GB of nPA $(889.0 \mathrm{~kJ} / \mathrm{mol})$ is similar to that of Phe $(888.9$ $\mathrm{kJ} / \mathrm{mol})$ and Thr $(888.5 \mathrm{~kJ} / \mathrm{mol})$, one would expect that ternary complex formation would be strongest for these amino acids. By this reasoning, GBs of Ala and Val would be too low relative to nPA to support a strong ion/dipole complex so that only guest-exchange reactions would be observed. However, the results show that Thr yielded only products corresponding to guest-

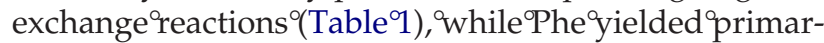
ily the ternary complex. Additionally, amino acids that are significantly more basic than $n$-propylamine should

Table 1. The reaction of the amino acid complexes of $\beta$-CD with n-propylamine and ethylenediamine. For the Bowers results, the charge solvated (CS) species formed with Gly and Ala, as observed in this study. They also reported a combination of charge solvated and zwitterionic (Z) species for Val and Leu, which is consistent with this study

\begin{tabular}{|c|c|c|c|c|}
\hline \multicolumn{2}{|c|}{ Amino acid } & \multirow{2}{*}{$\frac{\mathrm{GB}^{(\mathrm{a})}}{852.2}$} & \multirow{2}{*}{$\begin{array}{c}\begin{array}{c}\text { This } \\
\text { work }^{(b)}\end{array} \\
E\end{array}$} & \multirow{2}{*}{$\frac{\text { Bowers }^{(\mathrm{c})}}{\mathrm{CS}}$} \\
\hline Hydrocarbon & Gly & & & \\
\hline & Ala & 867.7 & $\mathrm{E}$ & $\mathrm{CS}$ \\
\hline & Val & 876.7 & $E / T(90)^{(e)}$ & $\mathrm{CS}\left(\mathrm{Na}^{+}\right) / Z\left(\mathrm{Cs}^{+}\right)$ \\
\hline & Leu & 880.6 & $\mathrm{E} / \mathrm{T}(0.4)^{(\mathrm{e})}$ & $\mathrm{CS}\left(\mathrm{Na}^{+}\right) / \mathrm{Z}\left(\mathrm{Cs}^{+}\right)$ \\
\hline & Phe & 888.9 & $\mathrm{E} / \mathrm{T}(0.2)^{(\mathrm{e})}$ & z \\
\hline \multirow[t]{8}{*}{ Heteroatoms } & Cys & 869.3 & $E$ & CS \\
\hline & Asp & 875.0 & $\mathrm{E}$ & \\
\hline & Glu & 879.1 & $\mathrm{~T}$ & \\
\hline & Ser & 880.7 & E & CS \\
\hline & Thr & 888.5 & E & \\
\hline & Tyr & 892.1 & $\mathrm{~T}$ & \\
\hline & Asn & 891.5 & $\mathrm{~T}$ & \\
\hline & Met & 901.5 & $\mathrm{~T}$ & \\
\hline \multirow[t]{3}{*}{ Basic } & $\mathrm{His}^{(\mathrm{d})}$ & 950.2 & $\mathrm{~T}$ & Z \\
\hline & Lys $^{(d)}$ & 951.0 & $\mathrm{~T}$ & Z \\
\hline & $\operatorname{Arg}^{(d)}$ & 1007.0 & $\mathrm{~T}$ & Z \\
\hline
\end{tabular}

a Gas phase basicities are from literature [52].

$\mathrm{b} \mathrm{E}=$ guest exchange reaction and $\mathrm{T}=$ Ternary complex formation.

${ }^{\mathrm{c}} \mathrm{CS}=$ charge solvation and $\mathrm{Z}=$ zwitterionic form. $\mathrm{CS}$ and $\mathrm{Z}$ are from the literature [21].

d Reacted with ethylene diamine.

e Ratio of $E / T$ products. 


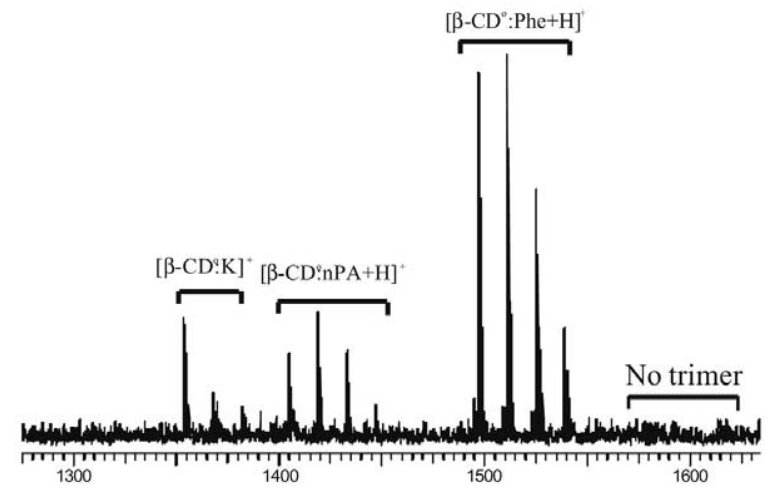

Figure 8. The reaction of di-O-methyl $\beta$-cyclodextrin $\left(\beta-\mathrm{CD}^{\circ}\right)$ and Phe complex with nPA. The spectrum has two sets of peaks. One set is the $\left[\beta-\mathrm{CD}^{\circ}: \mathrm{nPA}+\mathrm{H}\right]^{+}$complex around $1400 \mathrm{~m} / \mathrm{z}$ and the other set is the $\left[\beta-\mathrm{CD}^{\circ}: \text { Phe }+\mathrm{H}\right]^{+}$complex around $1500 \mathrm{~m} / \mathrm{z}$. The reaction with $\beta-\mathrm{CD}^{\circ}$ does not produce the ternary complex.

either produce only exchange reactions, albeit slowly, or not react at all. Studies with $\beta$-CD* show no reaction between the complexes of His, Lys and Arg with n-propylamine ${ }^{\circ}[44] .{ }^{\circ}$ More $^{\circ}$ basic $^{\circ}$ alkyl $^{\circ}$ amines $^{\circ}$ were needed to produce exchange reactions with His and Lys. The Arg complex $\left[\beta-\mathrm{CD}^{*}: \mathrm{Arg}+\mathrm{H}\right]^{+}$was essentially unreactive with all the amines we examined. However with $\beta-\mathrm{CD}$, amino acids more basic that $\mathrm{nPA}$, including Arg, produced the ternary complexes as the primary products.

The reaction with EDA $(912.5 \mathrm{~kJ} / \mathrm{mol})$ and the amino acid complexes of $\beta$-CD yielded the same reactions as nPA for all the amino acids, however the rates of the reactions were noticeably faster for EDA than nPA. An ion/dipole complex should again favor stronger interactions when the gas-phase basicities of the amino acid and EDA are most similar. The GB of EDA is comparable to that of Met, however the ternary complexes were still observed with amino acids with much lower basicity such as Leu. The reaction rates were noticeably faster with EDA than $\mathrm{nPA}$. We can conclude that differences in GB between the amino acids and alkyl amine do not play a direct role in the formation of either exchange product or the ternary complex for $\beta$-CD. The only apparent trend in the reactivity is that amino acids with large GB tend to produce the ternary complexes.

The reaction of partially methylated cyclodextrin, $\beta$-CD ${ }^{\circ}$, provide indications for the importance of the narrow rim in the stabilization of the ternary complexes. Partially methylated $\beta$-cyclodextrin is often a mixture of compounds with varying degrees of methylation. The 7-methyl product involves complete methylation of the narrow rim, as the 6-hydroxyl groups are the most kinetically reactive. The reaction of $\left[\beta-\mathrm{CD}^{\circ}:\right.$ Phe $\left.+{ }^{\circ} \mathrm{H}\right]^{+^{\circ}}$ complex $^{\circ}$ with $^{\circ}$ nPA ${ }^{\circ}$ is ${ }^{\circ}$ shown ${ }^{\circ}$ in ${ }^{\circ}$ Figure $^{\circ} 8 .{ }^{\circ}$ Four peaks around $1500 \mathrm{~m} / \mathrm{z}$ represent the complexes of Phe and $\beta-\mathrm{CD}^{\circ}$ with varying degrees of methylation. Three peaks around $1400 \mathrm{~m} / \mathrm{z}$ represent the guest-exchanged product, $\left[\beta-\mathrm{CD}^{\circ}: \mathrm{nPA}+\mathrm{H}\right]^{+}$complex. There are no peaks representing the ternary complex of $\beta-\mathrm{CD}^{\circ}$, which would be expected around $1560 \mathrm{~m} / \mathrm{z}$. Therefore, the derivatization of the narrow rim prevents the formation of ternary complexes.

\section{Ternary Complex Formation in Other Host Molecules}

The importance of hydroxyl groups on the rim is emphasized by the examination of two other hosts. Maltoheptaose is the linear analog to $\beta$-cyclodextrin. It is a more flexible and provides a "pseudo" cavity for amino acids. Protonated amino acids coordinated to permethylated maltoheptaose undergo only exchange reactions that are also enantioselective. For larger amino acids and peptides, the enantioselectivity is better with maltoheptaose as it provides a flexible host that can accommodate larger compounds ${ }^{\circ}[44]$. The ${ }^{\circ}$ amino $^{\circ}$ acids ${ }^{\circ}$ were ${ }^{\circ}$ investigated ${ }^{\circ}$ with $^{2}$ underivatized maltoheptaose, but no ternary complexes were observed (spectra not shown). It is likely that the linear oligosaccharide is not capable of producing the same well-defined, fixed-dimension structure of its cyclic analog. Experiments involving other cyclodextrins with smaller ( $\alpha$-cyclodextrin) and larger ( $\gamma$-cyclodextrin) narrow rim diameters are currently underway to examine this phenomenon.

The cyclodextrin cavity can be elongated with the use of 2-hydroxypropyl derivatives. The derivatives also allow the hydroxyl groups more flexibility when interaction with the amino acids. The derivatization is however difficult to complete often yielding partial substitutions. The host 2-hydroxypropyl $\beta$-cyclodextrin with 5 to 11 substitutions $(\mathrm{Hy}-\beta-\mathrm{CD})$ was examined

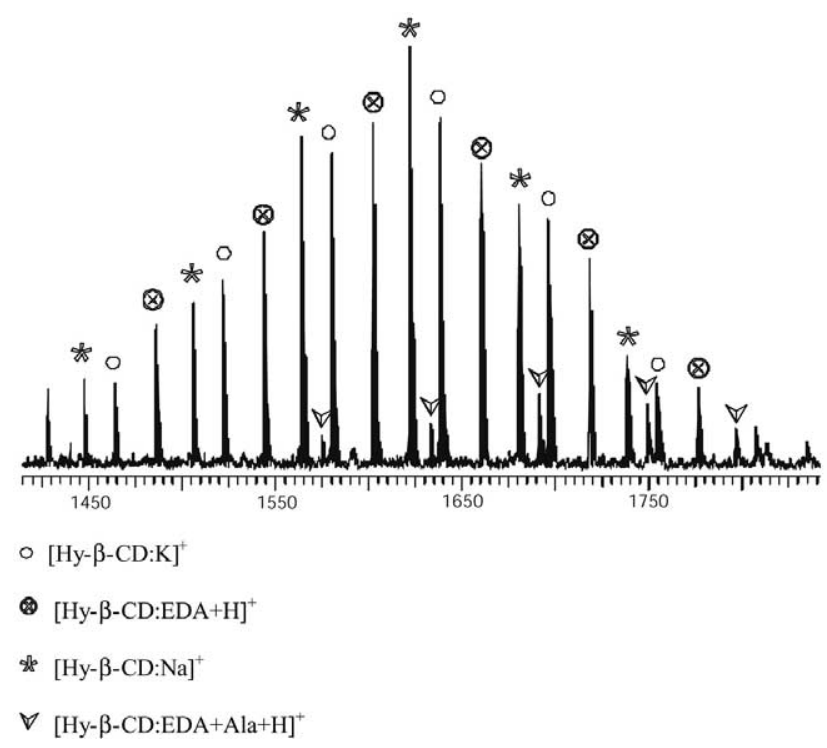

Figure 9. FTMS spectrum of the reaction of $[\mathrm{Hy}-\beta-\mathrm{CD}: \mathrm{Ala}+\mathrm{H}]^{+}$ complex. The Ala complex undergoes both the guest exchange reaction and the formation of the ternary complex. Ala complex with underivatized $\beta$-CD undergoes only the guest exchange reaction. (Hy- $\beta$-CD: 2-hydroxypropyl $\beta$-cyclodextrin, EDA: ethylenediamine). 
with a small number of amino acids. With $\mathrm{Hy}-\beta-\mathrm{CD}$, amino acids including Ala, Val, Leu and Phe yielded both ternary complexes and exchange products when

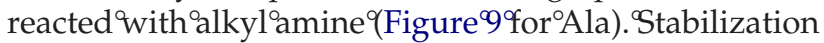
of the putative zwitterion complex even with the small and less basic amino acids Ala and Val is possible because the hydroxyl groups in the narrow rim are now more flexible and can better stabilize the nascent charges. Similarly, the elongation of the cavity prohibits the carboxylic acid from interacting with the wide rim forcing the entire molecule to interact primarily with the narrow rim thereby favoring zwitterion formation.

\section{Discussion}

The theoretical and experimental evidences when taken together point to the ternary complexes as being zwitterionic species and not some form of non-specific ion/dipole complex. The most compelling evidence is found in the comparison between the derivatized and underivatized cyclodextrins. With $\beta-\mathrm{CD}^{*}$ only exchange reaction is observed while with $\beta-C D$, the ternary complex is also observed. We have localized the important interactions as those involving the narrow rim of the cyclodextrin and the amino acid. When the hydroxyl groups are not present, the ternary complexes are not formed. There is no apparent reason for the formation of the ion/dipole complex to be favored with such specificity. Ternary complex formation favors the presence of a free carboxylic acid on the amino acid, free hydroxyl groups on the narrow rim, and basic amino acids.

The ternary complex is formed when the carboxylic acid group of the amino acid is deprotonated creating a zwitterion ionic species. The nascent ammonium group of the alkyl amine remains attached forming a saltbridge interaction that further stabilizes the complex. This interaction is further stabilized by hydrogen bonding interactions provided by the hydroxyl groups on the narrow rim of the cyclodextrin (Scheme 4). When this interaction is absent as in the derivatized hosts $\beta-C D^{*}$ and $\beta-C D^{\circ}$, the salt-bridge complex is not stable.

For amino acids that produce both exchange and ternary complex products, we posit that both complexes threaded-through and narrow-only, were produced during the electrospray ionization of the amino acidcyclodextrin complexes. The threaded-through orientation produced exchange products, while the narrowonly orientation produced the zwitterion and hence ternary complexes.

The comparison of this data to those of Bowers and co-workers who studied gas-phase zwitterionic formation of amino acids coordinated to $\mathrm{Na}^{+}$and $\mathrm{Cs}^{+}$yielded surprisingly ${ }^{\circ} \operatorname{good}^{\circ} \operatorname{agreement}^{\circ}\left(\text { Table }^{\circ} 1\right)^{\circ}\left(\operatorname{see}^{\circ}\right.$ also $^{\circ}[50,051]$ [21])..$^{\circ}$ The $^{\circ}$ amino $^{\circ}$ acids $^{\circ}$ that $^{\circ}$ form $^{\circ}$ zwitterions $^{\circ}$ in $^{\circ}$ the cyclodextrin also form zwitterions when coordinated with $\mathrm{Cs}^{+}$more so than with $\mathrm{Na}^{+}$. The other notable trend for the alkali metal ions is that the propensity for zwitterion ion formation increases with the basicity of the amino acid. The same general trend is observed with the cyclodextrins complexes. However, there are variations such as Leu, Phe, and Glu, which produce zwitterions despite the relatively low basicities of these compounds. Some of these discrepancies may be attributed to the coordinating effect of the cyclodextrin rim.

\section{Conclusion}

The production of zwitterions easily and efficiently in cyclodextrin cavities may provide a readily available source of different types of zwitterions. These methods could in turn produce abundances suitable for gasphase spectroscopic studies. Additionally, cyclodextrins provide "solvated" systems for studying gasphase zwitterionic species. The comparison of the results between the ion trap and the ICR is revealing. Complexes formed by ion molecule reactions are generally better stabilized in the ion trap because the pressure is at least three to four orders of magnitude greater. Because the ratio of the products is similar, it suggests that the ternary complexes are long-lived. Similarly, the presence of two distinct rate constants with Leu for the formation of the ternary complex and the exchange product further indicates that there is little or no conversion from one to the other. The two products may be a reflection of two types of amino acid-cyclodextrin interaction-one leads to guest exchange and the other to ternary complex formation. The theoretical calculations suggest the differences are attributable to two types of interactions for the amino acid-one in which the amino acid reacts primarily with the narrow rim to yield the ternary complex and the other where the amino acid interacts with both the narrow and wide rim to yield the exchange product.

Stabilization of the amino acid zwitterion is favorable when there is a coordinating charge. Earlier studies show that alkali metal ions are sufficient but this study shows that ammonium ions can similarly stabilize the complex in the presence of extensive hydrogen bonding. The presence of other hydrogen bonding interactions also increases the stability of zwitterionic saltbridge complexes. There is ample evidence provided in the literature that is consistent with these observations.

The enduring question is how many water molecules are necessary to stabilize the glycine zwitterion. These results show that Ala is stabilized by seven hydroxyl
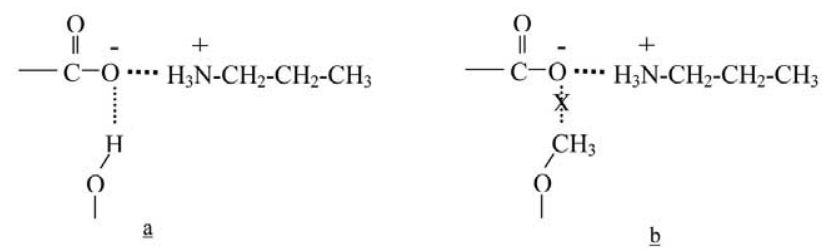

Scheme 4. The hydroxyl groups on the narrow rim of underivatized $\beta$-cyclodextrin can better stabilize the salt bridge-zwitterionic complexes (a). The methoxyl groups are not able to stabilize the complexes (b). 
groups if they are relatively unconstrained as in the 2 -hydroxypropyl $\beta$-cyclodextrin host. If a water molecule is to provide two hydrogen bonding interaction, then the seven hydroxyl groups could represent three to four water molecules. These results would be in line with ${ }^{\circ}$ those ${ }^{\circ}$ by $^{\circ}$ and $^{\circ} \mathrm{Jockush}^{\circ} \mathrm{et}^{\circ} \mathrm{al}^{\circ}{ }^{\circ} \mathrm{Kassab}^{\circ} \mathrm{et}^{\circ}$ al. ${ }^{\circ}\left[26,{ }^{\circ} 17\right]$. Although there are seven hydroxyl groups in the narrow rim of $\beta$-cyclodextrin, it is not clear how many are necessary to stabilize the complex. There are structural factors as well such as the size of the cavity and the orientation of the hydroxyl groups. While these may seem to complicate the system further, they are instead opportunities for examining zwitterions in small well defined systems.

\section{References}

1. Vickers, S.; Polsky, S. L. The biotransformation of nitrogen containing xenobiotics to lactams. Curr. Drug Metab. 2000, 1, 357-389.

2. Kvamme, E.; Roberg, B.; Torgner, I. A. Glutamine transport in brain mitochondria. Neurochem. Int. 2000, 37, 131-138.

3. Twhwaties, D. T.; Stevens, B. C. Exp. Physiol. 1999, 84, 275-284.

4. Pineda, M.; Fernandez, E.; Torrents, D.; Esteves, R.; Lopez, C.; Camps, M.; Lloberas, J.; Zorzano, A.; Palacin, M., et al. Identification of a membrane protein, LAT-2, that co-expresses with 4F2 heavy chain, an L-type amino acid transport activity with broad specificity for small and large zwitterionic amino acids. J. Biol. Chem. 1999, 274, 19738-19744.

5. Hatanaka, T.; Kamon, T.; Uozumi, C.; Morigaki, S.; Aiba, T.; Katayama, K.; Koizumi, T. Influence of $\mathrm{pH}$ on skin permeation of amino acids. J. Pharm. Pharmacol. 1996, 48, 675-679.

6. Wu, X.; Geroge, R. L.; Huang, W.; Wang, H.; Conway, S. J.; Leibach, H. F.; Ganapathy, V. Biochim. Biophys. Acta 2000, 1466, 315-327.

7. Raposo, C.; Wilcox, C. S. The intramolecular salt effect in chiral auxiliaries. Enhanced diastereoselectivity in a nitrile oxide cycloaddition via rational transition state stabilization. Tetrahedron Lett. 1999, 40, 1285-1288.

8. Spencer, T. A.; Onofrey, T. J.; Cann, R. O.; Russel, J. S.; Lee, L. E.; Blanchard, D. E.; Castro, A.; Gu, P.; Jiang, G.; Shecter, I. Zwitterionic sulfobetaine inhibitors of squalene synthase. J. Org. Chem. 1999, 64, 807-818.

9. Theodore, T. R., Van Zandt, R., Carpenter R. H. Preliminary evaluation of a fixed dose of zwitterionic piperazine (TVZ-7) in clinical cancer. CANCER Biother. Rad. 1997, 12, 351-353.

10. Kim, E.; Paliwal, S.; Wilcox, C. S. Measurements of molecular electrostatic field effects in edge-to-face aromatic interactions and $\mathrm{CH}$-interactions with implications for protein folding and molecular recognition. J. Am. Chem. Soc. 1998, 120, 1119211193.

11. Gordon, M. S.; Jensen, J. H. Understanding the hydrogen bond using quantum chemistry. Acc. Chem. Res. 1996, 29, 536-543.

12. Jensen, J. H.; Gordon, M. S. On the number of water molecules necessary to stabilize the glycine zwitterion. J. Am. Chem. Soc. 1995, 117, 8159-8170.

13. Chapo, C. J.; Paul, J. B.; Provencal, R. A.; Roth, K.; Saykally, R. J. Is arginine zwitterionic or neutral in the gas phase? Results from IR cavity ringdown spectroscopy. J. Am. Chem. Soc. 1998, 120, 12956-12957.

14. Ryan, R. J.; Hodyss, R.; Beauchamp, J. L. Salt bridge stabilization of charged zwitterionic arginine aggregates in the gas phase. J. Am. Chem. Soc. 2001, 123, 3577-3583.

15. Suenram, R. D.; Lovas, F. J. Millimeter wave spectrum of glycine. A new conformer. J. Am. Chem. Soc. 1980, 102, 7180-7184.
16. Wang, X. B.; Broadus, K. M.; Wang, L. S.; Kass, S. R. Photodetachment of the first zwitterionic anions in the gas phase: probing intramolecular coulomb repulsion and attraction. J. Am. Chem. Soc. 2000, 122, 8305-8306.

17. Kassab, E.; Langlet, J.; Evleth, E.; Akacem, Y. Theoretical study of solvent effect on intramolecular proton transfer of glycine. J. Molec. Struct. (Theochem) 2000, 531, 267-282.

18. Broadus, K. M.; Kass, S. R. Probing electrostatic effects: Formation and characterization of zwitterionic ions and their "neutral" counterparts in the gas phase. J. Am. Chem. Soc. 2000, 122, 9014-9018.

19. Jockush, R. A.; Price, W. D.; Williams, E. R. Structure of cationized arginine (Arg. $\mathrm{M}+, \mathrm{M}=\mathrm{H}, \mathrm{Li}, \mathrm{Na}, \mathrm{K}, \mathrm{Rb}$, and $\mathrm{Cs}$ ) in the gas phase: Further evidence for zwitterionic arginine. $J$. Phys. Chem. A 1999, 103, 9266-9274.

20. Price, W. D.; Jockusch, R. A.; Williams, E. R. Is arginine a zwitterion in the gas phase? J. Am. Chem. Soc. 1997, 119, 1198811989 .

21. Wyttenbach, T.; Witt, M.; Bowers, M. T. On the stability of amino acid zwitterions in the gas phase: The influence of derivatization, proton affinty, and alkali ion addition. J. Am. Chem. Soc. 2000, 122, 3458-3464.

22. Wyttenbach, T.; Bushnell, J. E.; Bowers, M. T. Salt bridge structures in the absence of solvent? The case for the oligoglycines. J. Am. Chem. Soc. 1998, 120, 5098-5103.

23. Wyttenbach, T.; Witt, M.; Bowers, M. T. On the question of salt bridges of cationized amino acids in the gas phase: Glycine and arginine. Int. J. Mass Spectrom. 1999, 182, 243-252.

24. Wang, W.; Pu, X.; Zheng, W.; Wong, N. B.; Tian, A. Some theoretical observations on the 1:1 glycine zwitterion-water complex. J. Molec. Struct. (Theochem) 2003, 626, 127-132.

25. Julian, R. R.; Beauchamp, J. L.; Goddard, W. A., III. Cooperative salt bridge stabilization of gas-phase zwitterions in neutral arginine clusters. J. Phys. Chem. A 2002, 106, 32-34.

26. Jockusch, R. A.; Lemoff, A. S.; Williams, E. R. Hydration of valine-cation complexes in the gas phase: On the number of water molecules necessary to form a zwitterion. J. Phys. Chem. A 2001, 105, 10929-10942.

27. Jockusch, R. A.; Lemoff, A. S.; Williams, E. R. Effect of metal ion and water coordination on the structure of a gas-phase amino acid. J. Am. Chem. Soc. 2001, 123, 12255-12265.

28. Cerda, B. A.; Wesdemiotis, C. $\mathrm{Li}+, \mathrm{Na}+$, and $\mathrm{K}+$ Binding to the DNA and RNA Nucleobases. Bond Energies and Attachment Sites from the Dissociation of Metal Ion-Bound Heterodimers. J. Am. Chem. Soc. 1996, 118, 11884-11892.

29. Kish, M. M.; Ohanessian, G.; Wesdemiotis, C. The $\mathrm{Na}^{+}$affinities of amino acids: side-chain substituent effects. Int. J. Mass Spectrom. 2003, 227, 509-524.

30. Hoyau, S.; Ohanessian, G. Interaction of alkali metal cations $(\mathrm{Li}+-\mathrm{Cs}+)$ with glycine in the gas phase: A theoretical study. Chem-Eur J 1998, 4, 1561-1569.

31. Wong, C. H. S.; Siu, F. M.; Ma, N. L.; Tsang, C. W. A theoretical study of potassium cation-glycine $(\mathrm{K}+-\mathrm{Gly})$ interactions. $J$. Mol. Struct. (Theochem) 2002, 588, 9-16.

32. Talley, J. M.; Cerda, Blas A.; Ohanessian, G.; Wesdemiotis, C. Alkali metal ion binding to amino acids versus their methyl esters: Affinity trends and structural changes in the gas phase. Chem-Eur J 2002, 8, 1377-1388.

33. Ryzhov, V.; Dunbar, R. C.; Cerda, B.; Wesdemiotis, C. Cation-Effects in the complexation of $\mathrm{Na}+$ and $\mathrm{K}+$ with Phe, Tyr, and Trp in the gas phase. J. Am. Soc. Mass Spectrom. 2000, 11, 1037-1046.

34. Locke, M. J.; Hunter, R. L.; McIver, R. T., Jr. Experimental Determination of the Acidity and Basicity of Glycine in the Gas Phase. J. Am. Chem. Soc. 1979, 101, 272-273.

35. Siu, F. M.; Ma, N. L.; Tsang, C. W. Cation-pi interactions in sodiated phenylalanine complexes: Is phenylalanine in the 
charge-solvated or zwitterionic form? J. Am. Chem. Soc. 2001, 123, 3397-3398.

36. Minyaev, R. M.; Starikov, A. G.; Minkin, V. Stabilization of the glycine zwitterionic form by complexation with $\mathrm{Na}+$ and $\mathrm{Cl}-$ : An ab initio study. Mendelev. Commun. 2000, 2, 43-44.

37. Winkle, L. J. V.; Campione, A. L.; Gorman, J. M. Na+independent transport of basic and zwitterionic amino acids in mouse blastocysts by a shared system and by processes which distinguish between these substrates. J. Biol. Chem. 1988, 263, 3150-3163.

38. Cerda, B. A.; Wesdemiotis, C. Zwitterionic versus chargesolvated structures in the binding of arginine to alkali metal ions in the gas phase. Analyst (Cambridge, U.K.) 2000, 125, 657-660.

39. Rak, J.; Skurski, P.; Gutowski, M. An ab initio study of the betaine anion-dipole-bound anionic state of a model zwitterion system. J. Chem. Phys. 2001, 114, 10673-10681.

40. Ramirez, J.; He, F.; Lebrilla, C. B. Gas-phase chiral differentiation of amino acid guests in cyclodextrin hosts. J. Am. Chem. Soc. 1998, 120, 7387-7388.

41. Ramirez, J.; Ahn, S.; Grigorean, G.; Lebrilla, C. B. Evidence for the formation of gas-phase inclusion complexes with cyclodextrins and amino acids. J. Am. Chem. Soc. 2000, 122, 6881-6890.

42. Ciucanu, I.; Kerek, F. Derivatization of Cyclodextrins. Carbohydr. Res. 1984, 131, 209-217.

43. Gard, E. E.; Green, M. K.; Warren, H.; Camara, E. J. O.; He, F.; Penn, S. G.; Lebrilla, C. B. A dual vacuum chamber Fourier transform mass spectrometer with rapidly interchangeable FAB, MALDI, and ESI Sources: Electrospray results. Int. J. Mass Spectrom. Ion Processes 1996, 157/158, 115-127.

44. Ahn, S.; Ramirez, J.; Grigorean, G.; Lebrilla, C. B. Chiral Recognition in gas-phase cyclodextrin: amino acid com-
plexes-Is the three point interaction still valid in the gas phase? J. Am. Soc. Mass Spectrom. 2001, 12, 278-287.

45. Penn, S. G.; He, F.; Lebrilla, C. B. Peptides complexed to cyclodextrin fragment rather than dissociate when subjected to blackbody infrared radiation D. J. Phys. Chem. 1998, 102, 9119-9126.

46. Gronert, S.; Pratt, L. M.; Mogali, S. Sustituent effects in gas-phase substitutions. Solvation reverses SN2 Substituent Effects. J. Am. Chem. Soc. 2001, 123, 3081-3091.

47. Flores, A. E.; Gronert, S. The gas-phase reactions of dianions with alkyl bromides: Direct identification of $\mathrm{S}(\mathrm{N}) 2$ and E2 products. J. Am. Chem. Soc. 1999, 121, 2627-2628.

48. Meot-Ner (Mautner), M. The ionic hydrogen bond and ion solvation. 1. $\mathrm{NH}+-\mathrm{O}, \mathrm{NH}+-\mathrm{N}$, and $\mathrm{OH}+-\mathrm{O}$ bonds. Correlations with proton affinity. Deviations due to structural effects. J. Am. Chem. Soc. 1984, 106, 257-264.

49. Meot-Ner (Mautner), M. The ionic hydrogen bond and ion solvation. 2. Solvation of onium ions by one to seven water molecules. Relations between monomolecular, specific, and bulk hydrogen. J. Am. Chem. Soc. 1984, 106, 1265-1272.

50. Hoyau, S.; Norrman, K.; McMahon, T. B.; Ohanessian, G. A quantitative basis for a scale of $\mathrm{Na}+$ affinities of organic and small biological molecules in the gas phase. J. Am. Chem. Soc. 1999, 121, 8864-8875.

51. Jensen, F. Structure and stability of complexes of glycine and glycine methyl analogues with $\mathrm{H}+, \mathrm{Li}+$, and $\mathrm{Na}+$. J. Am. Chem. Soc. 1992, 114, 9533-9537.

52. Hunter, E. P. L.; Lias, S. G. Evaluated gas phase basicities and proton affinities of molecules: An update. J. Phys. Chem. Ref. Data 1998, 27, 413-656. 